\title{
Development of Theoretical Framework for Management Departments' Ranking Systems in Jordanian Universities
}

\author{
Ahmad Al Adwan ${ }^{1}$, Ahmad Yousef Areiqat ${ }^{2} \&$ Ahmad M. A. Zamil ${ }^{3}$ \\ ${ }^{1}$ Marketing Department, Business School, Al-Ahliyya Amman University, Amman, Jordan \\ ${ }^{2}$ Department of Business Administration, Business School, Al-Ahliyya Amman University. Amman Jordan \\ ${ }^{3}$ Department of Marketing, College of Business Administration, Prince Sattam bin Abdulaziz University, 165 \\ Al-Kharj 11942, Saudi Arabia \\ Correspondence: Ahmad M. A. Zamil, Department of Marketing, College of Business Administration, Prince Sattam \\ bin Abdulaziz University, 165 Al-Kharj 11942, Saudi Arabia.
}

Received: August 30, 2020

Accepted: October 2, 2020

Online Published: October 3, 2020

doi:10.5430/ijhe.v10n1p106

URL: https://doi.org/10.5430/ijhe.v10n1p106

\begin{abstract}
Numerous specialists and associations have invested energy into building managerial positioning frameworks by concentrating on various rules and different strategies. These frameworks produce various positions for establishment because of methodological contrasts that emerge from the determination of markers, loads, information assortment, and examination. This paper reports on the calculated and methodological contrasts in college positioning frameworks and focuses on the circumstance in the Hashemite Kingdom of Jordan.

The writing audit exhibits a bigger than anticipated requirement for a national positioning framework for Jordan to recognize the situation of a particular college contrasted with others. In a vital administration setting, policymakers need to create and send techniques related to the advanced education framework.

The instance of the positioning of the executive's divisions was analyzed to develop an establishment for a national field-based positioning framework. Therefore, a structure for positioning of the executive's divisions in Jordanian colleges is proposed.
\end{abstract}

Keywords: Management Departments' Ranking Systems, Strategic Management in Jordanian Universities

\section{Introduction}

Over twenty years after the US News REF and World Report REF distributed its issue on "America's Best Colleges", and almost 10 years since Shanghai Jiao Tong University distributed the Academic Ranking of World Universities (ARWU), First, college rankings present a straightforward and simple examination of instructive execution and profitability, broadly and across global limits REF. Second, by pointing out the attributes and execution of top colleges around the world, rankings have become significant for estimating instructive quality and greatness that are valid for Higher Educational Institutions (HEIs) REF. Third, given the significance of advanced education to social and monetary development and success, rankings are frequently deciphered as a pointer of a country's worldwide intensity REF.

Today, legislators usually allude to HEI rankings as a proportion of their country's monetary qualities and desires, and colleges use them to help set or characterize targets planning their presentation against the different measurements REF. Scholastics use rankings to reinforce their expert notoriety and status, and understudies use them to assist them with settling on decisions about where to consider REF.

Yet, do rankings provide suitable data about advanced education or measure what's significant? Is it generally something worth being thankful for when a college climbs the rankings and breaks into the main 100? Do rankings increase expectations by empowering rivalry, or do they subvert the more extensive strategic give instruction? Do rankings upgrade vital dynamics by governments and establishments, or are there better strategies? Is it an opportunity to move past rankings?

In recent years, numerous college positioning frameworks that rely upon a chosen set of markers and delivering positioning tables dependent on these pointers have been created, REFS. They include different sorts of national and global positioning frameworks, creating arrangements of colleges dependent on multiple markers and a solitary 
pointer. These positioning frameworks rely upon a few elements including nation explicit conditions, training frameworks of nations, desires, and societies REFS.

Global positioning frameworks rely upon multiple markers, and through applying a suitable load as well as conglomerating them to each marker, an all-out score is acquired. The vitality and handiness of these worldwide frameworks are valid and positioning scholarly foundations by a solitary score has been a subject of discussion REFS.

Whether these positioning records are reasonable or not in the situation of mirroring the presentation of colleges REF. This perspective depends on the possibility that nation explicit conditions and the fundamental focal point of colleges are generally disregarded in the development of worldwide positioning frameworks REF.

National frameworks are more fit for dealing with local and social variables as they are built for nation explicit purposes REF. At the point when a positioning's degree is national it is bound to deliver a more exact rundown. Particularly in key administration settings; chiefs or government officials can take important activities to improve the nature of advanced education. These frameworks have a noteworthy potential to build the nature of scholastic establishments REF.

This paper studies the improvement of a theoretical structure for the leader's divisions' situating systems in Jordanian schools. which will stimulate universities' quality improvement exercises. Does the Jordanian Higher Education System require a propelled national structure that assesses schools by joining a couple of models addressing different aspects. It is essential to explore worldwide situating structures and to benchmark against the Jordanian System, and this paper describes the development of a national situating structure that centers around the leader's divisions of Jordanian universities. A review of worldwide and national rankings systems will happen, their impacts on authoritative issues of schools discovered, exercises of improving these structures taken into account, and a discussion to find ways to improve the theoretical structure.

\section{Literature Review}

Worldwide university rankings have the advantage of approaching numerous "authentic" information accessed through government organizations, as well as information from studies of understudies, overseers, and managers, and bibliometric investigations REFS. Though these conditions frequently don't apply all the time, as little information on foundations remains openly accessible, reviews are not directed either in light of cost or political contemplations, and distributions in globally perceived diaries are not many REFS. There are nearly 20 arrangements of college rankings in the creating scene, and this paper will show how worldwide rankings work in these situations, and how they vary from those found in the created world, both in reason and narrowing.

The paper will discover how web rankings, e.g. webometrics, have come to such tremendous noticeable quality in the creating scene and why they might stay at the "highest quality level" in numerous nations in the following years. The paper will conclude with certain considerations on the most proficient method to improve rankings in creating nations-(IREG-5 Conference:2010). While the quantity of worldwide and nation level positioning and grouping frameworks keeps on growing, a local order and evaluation of advanced education foundations in the Middle East and North Africa (MENA) area have not been created to-date. Such a framework is especially required given the fast extension of the advanced education area in the locale, as new local establishments and branch grounds of abroad organizations develop. Perceiving a critical requirement for dependable and exact organization-level information on advanced education establishments in the MENA district, the Institute of International Education (IIE) received funding from the Carnegie Corporation of New York to complete a pilot of creative examinations a framework for ordering and surveying advanced education foundations in the MENA locale REFS.

During the gathering meeting, key venture staff from the IIE and the Lebanese Association for Educational Studies (LAES) examined the flow status of the task and talked about the procedure, difficulties, and centrality of the exploration. The undertaking comprised the accompanying eight nations from the locale: Egypt, Lebanon, Jordan, Saudi Arabia, Qatar, UAE, Morocco, and Tunisia. This undertaking will assist with fortifying MENA organizations locally by providing benchmarks and key pointers against which they will have the option to quantify their development, as a way to contrast themselves with comparable establishments. The new grouping framework will simultaneously help create global enthusiasm for the district's foundations, which will bolster the auxiliary objective of the task to extend international linkages between MENA advanced education establishments and different organizations, to encourage information sharing, research cooperation, and institutional limit building. (El-Amine, 2010) 
Since 1983, the journal of U.S. News and World Reports has been releasing "America's Best Colleges" which uncovers the evaluation of American colleges regarding their academic's performance. These reports have accentuated the significance of the institutional picture and institutional notoriety, which is broadly utilized in instructive administrations to influence understudies' college choice procedure. Moreover, understudies' choices concerning whether remain at the college for additional examinations can be impacted by the institutional picture and the institutional notoriety of the college REF.

Nguyen and LeBlanc (2001) measured the connection of institutional picture and institutional notoriety with understudy's maintenance choices. They said that picking up knowledge into the job of institutional picture and notoriety is a powerful apparatus for the correspondence technique of the establishment. Scholarly organizations have the upside of taking key choices identified with asset distribution and upgrading their situations in positioning records.

Jarocka (2015) reported that the straightforwardness given by college rankings was instrumental in the administration of colleges. Jordanian understudies accept that rankings were significant in developing and guaranteeing notoriety. In light of an examination between colleges, positioning frameworks add to perform correlations and to alter the arrangement and the procedure to improve their exhibitions in rankings REF.

Notwithstanding colleges themselves, positioning frameworks are supporting components for partners in the assessment and dynamic procedures, by providing data straightforwardness for the understudies and their families REF.

Positioning frameworks can have a few structures as per the level, extension, center, and target gathering, for example, institutional, field-based, national, universal, instruction centered or research-centered positioning frameworks REF. As per the "European University Association", global rankings can be grouped in the way of college alliance tables speaking to a solitary totaled score of colleges, rankings exclusively center around research, multi-rankings delivering more than one rundown relying upon a lot of pointers and web rankings (Jarocka, 2012).

Worldwide positioning frameworks rely upon research information, exploration-based markers, and rank colleges dependent on their examination exhibitions and the presence of effectively available information because of bibliometric investigations. Frameworks are required to assess colleges from different angles by thinking about the enhancement of fields of study, and the focal point of colleges. Regarding creating real and dependable data for examination of colleges

Scholastic Ranking of World Universities (ARWU) is known as one of the most well-known global positioning frameworks which internationally ranks colleges dependent on research execution. Other pointers of the positioning structure comprise of graduated class and staff winning Nobel Prizes and Fields Medals, specialists in 21 expansive subject classifications, articles distributed in Nature and Science, and recorded in SCIE, SSCI, and scholastic execution comparative with institutional size. As such, every marker is measured and amassing as an all-out score for research execution (Liu and Cheng, 2005).

THE World University Ranking of "Times Higher Education" is another popular ranking system which was known as THE-QS World University Ranking between 2004 and 2009 as a result of cooperation with "QuacquarelliSymonds" (QS). After "Times Higher Education" started to align with "Thomson Reuters" in 2009, significant changes regarding to methodology and indicators were observed (Rauhvargers, 2011).

References per workforce, managers' perspectives, level of worldwide staff, and understudies independently and personnel/understudy proportion were different pointers that the framework considered (Saisana, d'Hombres ve Saltelli, 2011). After 2010, pointers that were related to the financial movement were remembered for THE-Thomson Reuters 2010 Ranking (Rauhvargers, 2011). Every one of these rankings is research centered.

Positioning specialists taking jobs in the positioning procedure led studies to assess the nature of different positioning frameworks, and they distributed 16 standards for surveying the positioning frameworks. These 16 standards are known as Berlin Principles (BP) and are the center of the review procedure of "Worldwide Ranking Expert Group" (IREG) for assessing positioning frameworks to give an endorsement of endorsement (Hagg and Wedlin, 2013).

The EU University-Based Research Assessments (AUBR), U-Map, U-Multirank, and AHELO are among different activities that rose out of giving an appraisal apparatus to colleges (Rauhvargers, 2011). They are positioning frameworks that offer intuitive web apparatuses, and clients, by choosing their preferred models were able to see the presentation profile of a particular field of study. 
U-Multirank considers advanced education foundations dependent on five measurements comprising of instructing and learning, research, information move, global direction, and local commitment (Jongbloed, Kaiser, and Vught 2013).

Concerning the Jordanian context, the nature of the research conducted by advanced education foundations of Jordan was assessed depending on the number of articles, number of references, articles per staff, references per staff, complete distributions, distributions per staff, number of Ph.D. understudies. The proportion of Ph.D. understudies, to the number of complete understudies and proportion of absolute understudies to scholarly staff express that the URAP framework has the limit of establishing an establishment for a complex national positioning framework that can be created later on. It is critical to uncover potential improvement zones and confinements of the URAP framework since each subject field has its elements, the contrasts between subject fields and creating positioning records as needs be is accepted to concoct more practical outcomes than a wholistic positioning methodology. A significant conceivable improvement bearing of URAP is the thought of field-based contrasts (Zamil, and Areiqat, 2020)

\section{Study Aim}

This investigation was built upon many markers for a field-based framework, by coordinating alternate points of view on execution. The extent of this examination included the board; as it is normal that the primary commitment of this investigation is the meaning of measurements, markers, and information hotspots for assessing the board divisions in Jordan.

Assessment of the circumstance in Jordan demonstrated that Jordanian colleges lacked markers that measured the colleges from alternate points of view, e.g. instructing or scholarly staff. There is a necessity for a framework in Jordan that will evaluate colleges nearly by including local variables and assortments among fields of study and offices.

These discoveries and pointers of different positioning frameworks will assist the production of the applied structure and policymakers of advanced education. Foundations were characterized as the objective gathering for the positioning framework toward the start of the investigation. As far as vital administration for advanced education establishments.

\section{Selection of Components and Indicators}

The extent of the examination considered all foundations of the Jordanian Higher Education System that have the executive divisions. As indicated by advanced education measurements of the Council of Higher Education, there are roughly 170 administration offices in 28 Jordanian colleges (http://portal.jordan.gov.jo/).

The writing survey on field-based frameworks. CHE, U-Map, and U-Multirank added to breaking down their measurements and pointers concerning their convenience in the board divisions of Jordanian colleges; as it is viewed as the most appropriate positioning instrument in the writing that is intended to conquer risky issues related with rankings.

This part involved markers that could be applied to every administrative field. where an overview was spread to understudies. This overview considered different angles identified with the nature of the scholarly projects. This review intends to investigate their perspectives about course content, course association, classes, and different offices, direction, the data innovation foundation, and the college's site; which are all segments accepted to influence the general quality presentation of the administration division. Different parts are as shown in the following figure:

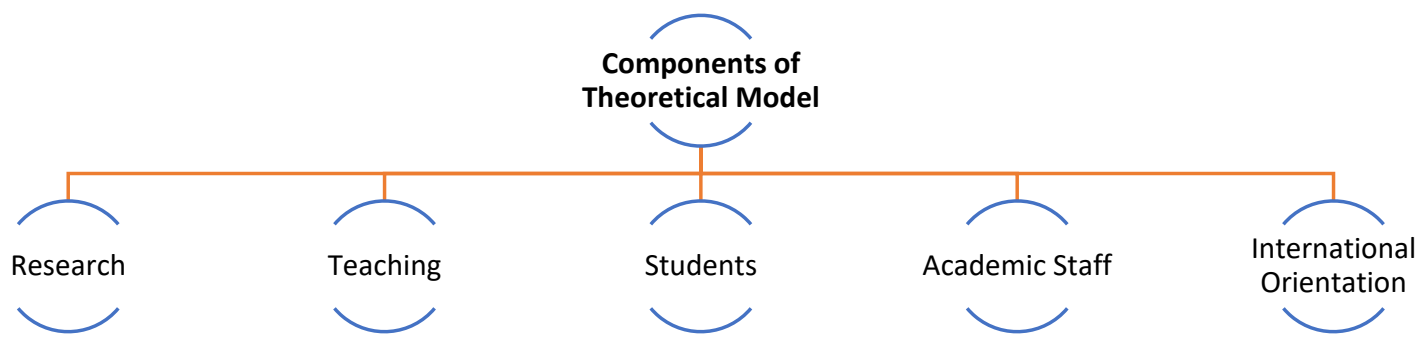

Figure 1. Components of theoretical model

In this investigation, the proposed positioning system for the board offices comprised five parts as observed in Fig.1. These segments are to be estimated for their quality exhibitions are research, scholarly staff, instructing, 
understudies, global direction, and generally speaking circumstances. These markers, their degree of evaluation, important loads of pointers, and the complete load of the parts are introduced as follows.

It is believed that performing college-level appraisals can be more exact because permeability, correspondence, and extension of a college by spreading data from a wide scope of fields are significant REFS. In this way, these pointers are joined with others estimating the measurement and a load of $10 \%$ is allotted to this segment.

To quantify "research quality", notwithstanding research efficiency pointers exhibiting appraisal on the field level, the proportion of the quantity of scholarly staff to the quantity of Ph.D. understudies and examination financial plan per scholarly staff are similarly considered. Owing to the perspective on specialists, the heaviness of "research quality" was recognized as $20 \%$, and the portion of the related load to every specific pointer can be found in Table 1 . According to Alma, B, Coşkun, E, and Övendireli, E. (2016).

Table1. Indicators for assessing the components

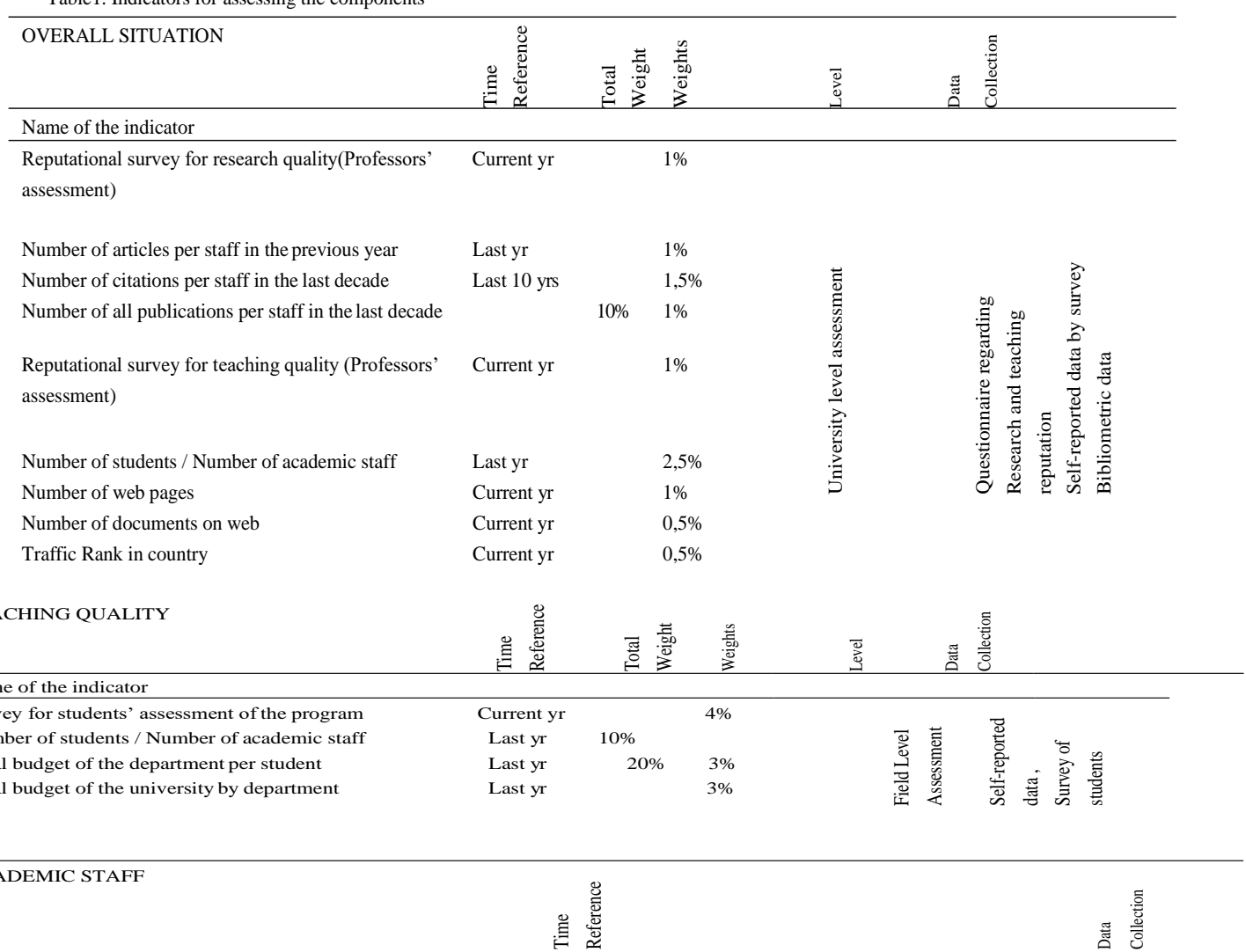

\begin{tabular}{|c|c|c|c|c|}
\hline RESEARCH QUALITY & 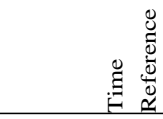 & 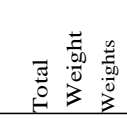 & ב্] & 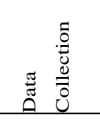 \\
\hline \multicolumn{5}{|l|}{ Name of the indicator } \\
\hline \multirow[t]{2}{*}{ Number of articles per staff in the previous year } & Last & $3 \%$ & & \\
\hline & yr & $4 \%$ & & \\
\hline Number of citations per staff & Last $10 \mathrm{yrs}$ & $20 \%$ & & 苞 $\quad \frac{\pi}{\pi}$ \\
\hline Number of all publications per staff in the last decade & Last 10 yrs & $5 \%$ & & $\overbrace{}^{0}$ \\
\hline Number of academic staff / Number of PhD students & Last yr & $5 \%$ & $\bar{\Xi} \stackrel{\square}{\square}$ & 常 ৯ \\
\hline Research budget per academic staff & Last yr & & 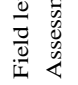 & 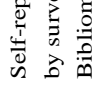 \\
\hline
\end{tabular}

Exploration efficiency boundaries or the number of articles per staff in the earlier year, the quantity of all distributions per staff in the most recent decade rely upon bibliometric information, and bibliometric examinations, are proposed to be the information source and the strategy for information assortment. To obtain information about the quantity of Ph.D. understudies, the quantity of scholarly staff and an examination spending plan of the 
executive's offices, genuine information from offices ought to be accumulated and a study ought to be directed for this reason. (Alma, Coşkun, and Övendireli, 2016).

Managing the "understudies" segment with a load of $20 \%$, this pointer is utilized in some positioning frameworks when performing nation-level appraisals because the contribution of the training corresponds with its yield and qualified understudies select their colleges likewise (Zamil\& Areiqat, 2020).

The internationalization of the board offices is assessed also and decided as another segment of the proposed calculated model with the name of "universal direction". The proportion of the number of local understudies to the number of unfamiliar understudies and the proportion of local scholarly staff to unfamiliar scholastic staff are estimated for evaluating the global direction. Loads of these markers are set to be $8 \%$ and $2 \%$ separately speaking to $10 \%$ all-out weight for the appraisal of worldwide direction.

\section{Information Assortment and Count of Scores}

For the aim and use of this study, proper personnel or regulatory staff have been addressed for obtaining pertinent information. Understudies were explored for showing quality by approaching inquiries for the program, course content, and other learning results. Inquiries of understudies' studies were identified with the administrative divisions of colleges, which offered the answers to handle explicit inquiries.

For the greater part of the markers, the executive's branches of colleges were evaluated by their score on a specific measurement. After the college showing the best score was appointed, the most elevated focuses, others in the rank were assigned scores. The heaviness of every segment was extraordinary and by applying these loads, the presentation profile of the administration office was resolved. On account of the scholarly staff measurement, a scale was produced for the workforce. Every scholarly staff received a score dependent on this scale and the total score was acquired by accumulating the outcomes.

\section{Conclusion}

This investigation attempted to build a calculated structure for a field-based college positioning framework. Writing survey studies and the global assessment of positioning frameworks were added to gain a better understanding of the methodological issues concerning rankings. Jordanian colleges have various fields of study and every college doesn't display a similar measure of execution in each field, which is a critical issue that warrants further investigation.

This system for the executive's divisions is intended to be a suitable tool for surveying these offices relatively and aiding vital administration issues. This examination can be the initial step to develop a more exhaustive field-based positioning framework for Jordan.

The execution of the proposed system and distribution of the rankings are among the possibilities for this investigation. Moreover, this positioning framework can be a reason for the improvement of a multi-positioning methodology that thinks about all fields of study and positions colleges in a multi-dimensional way later on.

\section{References}

Alma, B, Coşkun, E., \& Övendireli,E. (2016). University ranking systems and proposal of a theoreticalframework for ranking of Turkish Universities: A case of management departments. Procedia - Social and Behavioral Sciences, 235(2016), 128-138. https://doi.org/10.1016/j.sbspro.2016.11.008

El-Amine, Adnan. (2010). Classifying Higher Education Institutions in the MENA Region [Middle East and North Africa]: A Pilot Study.

Hazelkorn, Ellen. (2013). How Rankings are Reshaping Higher Education. Centre for Social and Educational Research, Technological University Dublin.

IREG-5 Conference: The Academic Rankings: From Popularity to Reliability and Relevance, organized by: IREG Observatory on Academic Ranking and Excellence.

Jarocka, M. (2012). University ranking systems-from league table to homogeneous groups of universities. World Academy of Science, Engineering and Technology, 66, 800-805.

Jarocka, M. (2015). Transparency of University Rankings in the Effective Management of Universities. Business, Management, and Education, 13(1), 64-75. https://doi.org/10.3846/bme.2015.260

Jongbloed, B., Kaiser, F., \& Vught, F. (2013). U-Map and U-Multirank: profiling and ranking tools for higher education institutions (EAIR 35th Annual Forum in Rotterdam, The Netherlands, 28-31 August).

Juta and CHE Centre for Higher Educational Development, Guetersloh, Germany. Berlin, 6-8 October 2010. 
Liu, Nian Cai, \& Cheng, Ying. (2005). The Academic Ranking of World Universities. Higher Education in Europe, 30(2), 127-136. https://doi.org/10.1080/03797720500260116

Nguyen, N., \& LeBlanc, G. (2001). Image and reputation of higher education institutions in students' retention decisions. International Journal of Educational Management, 15(6), 303-311. https://doi.org/10.1108/EUM0000000005909

Rajika Bhandari, Deputy Vice President, Research and Evaluation, Institute of International Education (IIE), New York, USA.

Raughvargers, A. (2011). Global University Rankings and Their Impact. European University Association Report on Rankings.

Saisana, M., d'Hombres, B., \& Saltelli, A. (2011). Rickety numbers: Volatility of university rankings and policy implications. Research Policy, 40(1), 165-177. https://doi.org/10.1016/j.respol.2010.09.003

Vught, F., \& Ziegele, F. (2011). U-Multirank: design and testing the feasibility of a multidimensional global university ranking: Final report, Consortium for Higher Education, and Research Performance Assessment.

Zamil, A., \& Areiqat, A. (2020). The Impact of Accreditation of Higher Education Institutions in Enhancing the Quality of the Teaching Process. Talent Development \& Excellence, Vol.12, No.3s, 2020, 1912-1921.

\section{Copyrights}

Copyright for this article is retained by the author(s), with first publication rights granted to the journal.

This is an open-access article distributed under the terms and conditions of the Creative Commons Attribution license (http://creativecommons.org/licenses/by/4.0/). 